\title{
Article \\ Synchronization of the Glycolysis Reaction-Diffusion Model via Linear Control Law
}

\author{
Adel Ouannas ${ }^{1}$, Iqbal M. Batiha ${ }^{2,3}$, Stelios Bekiros ${ }^{4,5, * \mathbb{D}}$, Jinping Liu ${ }^{6}{ }^{\mathbb{D}}$, Hadi Jahanshahi ${ }^{7}$, Ayman A. Aly ${ }^{8}$ \\ and Abdulaziz H. Alghtani 8
}

1 Laboratory of Dynamical Systems and Control, University of Larbi Ben M'hidi, Oum El Bouaghi 04000, Algeria; ouannas.adel@univ-oeb.dz

2 Department of Mathematics, Faculty of Science and Technology, Irbid National University, Irbid 2600, Jordan; ibatiha@inu.edu.jo

3 Nonlinear Dynamics Research Center (NDRC), Ajman University, Ajman 346, United Arab Emirates

4 Department of Banking and Finance, FEMA, University of Malta, MSD 2080 Msida, Malta

5 LSE Health, Department of Health Policy, London School of Economics and Political Science, London WC2A 2AE, UK

6 Hunan Provincial Key Laboratory of Intelligent Computing and Language Information Processing, Hunan Normal University, Changsha 410081, China; Ljp202518@163.com

7 Department of Mechanical Engineering, University of Manitoba, Winnipeg, MB R3T 5V6, Canada; jahanshahi.hadi90@gmail.com

8 Department of Mechanical Engineering, College of Engineering, Taif University, P.O. Box 11099, Taif 21944, Saudi Arabia; aymanaly@tu.edu.sa (A.A.A.); a.ghtani@tu.edu.sa (A.H.A.)

* Correspondence: stelios.bekiros@eui.eu

check for updates

Citation: Ouannas, A.; Batiha, I.M.; Bekiros, S.; Liu, J.; Jahanshahi, H.; Aly, A.A.; Alghtani, A.H. Synchronization of the Glycolysis Reaction-Diffusion Model via Linear Control Law. Entropy 2020, 23, 1516. https:// doi.org/10.3390/e23111516

Academic Editor: António M. Lopes

Received: 14 October 2021

Accepted: 13 November 2021

Published: 15 November 2021

Publisher's Note: MDPI stays neutral with regard to jurisdictional claims in published maps and institutional affiliations.

Copyright: (c) 2021 by the authors. Licensee MDPI, Basel, Switzerland. This article is an open access article distributed under the terms and conditions of the Creative Commons Attribution (CC BY) license (https:/ / creativecommons.org/licenses/by/ $4.0 /)$.

\begin{abstract}
The Selkov system, which is typically employed to model glycolysis phenomena, unveils some rich dynamics and some other complex formations in biochemical reactions. In the present work, the synchronization problem of the glycolysis reaction-diffusion model is handled and examined. In addition, a novel convenient control law is designed in a linear form and, on the other hand, the stability of the associated error system is demonstrated through utilizing a suitable Lyapunov function. To illustrate the applicability of the proposed schemes, several numerical simulations are performed in one- and two-spatial dimensions.
\end{abstract}

Keywords: synchronization; linear control; asymptotic stability; reaction-diffusion model; lyapunov function; Selkov system; glycolysis system

\section{Introduction}

The development of control laws to achieve synchronization is one of the most valuable aspects in the analysis of the different behaviors of natural systems. Synchronization is necessary to increase our knowledge of a wide variety of naturalistic problems designed to meet the needs of biological processes associated, for instance, with living cells and the neuronal network technology. Such schemes can also be efficiently employed to improve the power of lasers, to encode and decode electronic messages, and to establish secure methods of communication [1]. In recent years, the synchronization of one-dimensional equations has been extensively examined and is broadly well-understood. In this regard, many methods and schemes have been developed to achieve the synchronization of ordinary differential equations (ODEs) and discrete maps, including the linear or nonlinear control scheme, the adaptive control approach, the active control scheme, the feedback control method [2-15], and various other types of synchronization, which can be found in [16-31]. However, the research dealing with synchronizing spatially extended systems described by reaction-diffusion systems (RDSs) is still limited.

Differential equations have wide applications in various engineering and science disciplines $[32,33]$. In chemistry, several chemical reaction models are described in the form of differential equations. Glycolysis, a basic chemical reaction occurring in the cytosol, is 
considered to be the typical example of a metabolic pathway for cellular energy [34]. The abundance of glycolysis makes it one of the ancient metabolic pathways for providing energy via the breakdown of glucose $\mathrm{C}_{6} \mathrm{H}_{12} \mathrm{O}_{6}$, into pyruvate, $\mathrm{CH}_{3} \mathrm{COCOO}^{-}+\mathrm{H}^{+}$[35]. The overall reaction of glycolysis is represented as follows [36]:

$$
\begin{gathered}
\mathrm{C}_{6} \mathrm{H}_{12} \mathrm{O}_{6}+2 \mathrm{NAD}^{+}+2 \mathrm{ADP}+2 \mathrm{P} \rightarrow 2 \text { pyruvicacid }, \\
\left(\mathrm{CH}_{3}(\mathrm{C}=\mathrm{O}) \mathrm{COOH}+2 \mathrm{ATP}+2 \mathrm{NADH}+2 \mathrm{H}^{+}\right) .
\end{gathered}
$$

Thus, glycolysis is a source of protons, and under increased oxygen-independent energy demands (during the exercise of muscles or cell proliferation), glycolysis may generate more protons and decrease the cytoplasmic $p H$. Selkov [37] presented a basic system that makes it possible to explain most experimental data on single-frequency oscillations in glycolysis qualitatively and which contains coupled first-order differential equations [38]. This system was then solved numerically by Mickens with the nonstandard finite difference scheme which preserves the property of positivity [39]. In the meantime, RDSs are usually used to describe certain realistic natural phenomena that can be involved in various processes such as neural networks, image processing, chemical reactions, and ecosystems. The presence of spatial variable means that such systems are frequently used in order to understand some irregular patterns such as self-replicating spikes, self-excitation, and spatio-temporal chaos. From this point of view and to further realize a wide variety of real-world problems, the importance of studying synchronization is highlighted for this model. In recent times, several considerable efforts have been made to examine the synchronization of RDSs, for example, in the bacterial cultures model [40], multi-layered natural networks [41], the FitzHugh-Nagumo system [42], and the Newton-Leipnik spatialtemporal chaotic system [43]. Moreover, appropriate controls have also been proposed for synchronizing different classes of partial differential equations (PDEs); see [44-49].

The present study concerns the analysis of the synchronization and control of the glycolysis model, which has the following general form:

$$
\left\{\begin{array}{l}
\frac{\partial u_{1}}{\partial t}=d_{1} \Delta u_{1}+f\left(t, u_{1}, u_{2}\right) \\
\frac{\partial u_{1}}{\partial t}=d_{2} \Delta u_{2}+g\left(t, u_{1}, u_{2}\right)
\end{array} \quad x \in \Omega, t>0\right.
$$

where

$$
\begin{gathered}
f\left(t, u_{1}, u_{2}\right)=b u_{2}-u_{1}+u_{1}^{2} u_{2} \\
g\left(t, u_{1}, u_{2}\right)=a-b u_{2}-u_{1}^{2} u_{2}
\end{gathered}
$$

and where $a, b, d_{1}, d_{2}$ are positive constants, and $\Omega \subset \mathbb{R}^{n}$ is a smoothly bounded domain with boundary $\partial \Omega, n \geq 1$.

The free-diffusion model was the first original glycolysis model proposed by E.E. Selkov to describe the metabolic pathway that converts a type of sugar (glucose) into cellular energy (ATP). For a detailed background on the derivation and biochemical significance of model (1), we encourage the interested reader to consult the excellent overviews given in [50].

The glycolysis model (1) has been extensively studied in recent decades, but most research has been dedicated to the dynamics and the behavior of solutions including steady-state solutions, spatio-temporal periodic solutions, pattern formation, and global attractors [51-54]. Nevertheless, to the authors' knowledge, this is the first study dealing with the synchronization and control of the RDS (1). This has motivated us to develop a suitable method to deal with the global synchronization of two glycolysis models. The remainder of this work is arranged in the following manner. In the next section, we discuss the existence and the uniform boundedness of the system's solution,which will be surely useful for the ensuing parts. In Section 3, we design an appropriate control law in its linear form and furthermore prove the global asymptotic stability of the trivial solution associated with the error synchronization system, which consequently implies a global 
synchronization of a couple of systems that have the same form of system (1). Section 4 presents some applications and numerical simulations that demonstrate our findings. Finally, Section 5 is devoted to stating the conclusion of this work.

\section{Problem Formulation}

This section examines model (1) in view of two main aspects-the existence and the boundedness of its solution. Our analysis is based on a significant result associated with this type of system, which was obtained by Selwyn et al. in [55]. First, we assume that system (1) satisfies the following non-negative and uniformly bounded initial conditions:

$$
0 \leq u_{1}(x, 0), u_{2}(x, 0) \leq M_{0}, \text { for all } x \in \Omega \text {, where } M_{0}>0,
$$

and the following homogeneous Neumann boundary conditions:

$$
\frac{\partial u_{1}}{\partial v}=\frac{\partial u_{2}}{\partial v}=0, \text { for all } x \in \partial \Omega, t>0,
$$

where $v$ is the unit vector normal to $\partial \Omega$. One might observe that system (1) satisfies the following properties:

1. Based on proposition 1 in [55] and since $f, g:[0, \infty)^{3} \rightarrow \mathbb{R}$ are continuous and differentiable functions in which $f(t, 0, \eta) \geq 0$ and $g(t, \xi, 0) \geq 0$, for all $t, \xi, \eta \geq 0$, we can deduce that system (1) has a local unique solution $\left(u_{1}, u_{2}\right)$ on $\Omega \times\left[0, T^{*}\right)$, and furthermore there are two continuous functions $N_{1}, N_{2}:\left[0, T^{*}\right) \rightarrow[0, \infty)$ such that:

$$
0 \leq u_{1}(x, t) \leq N_{1}(t), 0 \leq u_{2}(x, t) \leq N_{2}(t), \quad \text { where }(x, t) \in \Omega \times\left[0, T^{*}\right) .
$$

2. There is a constant $\gamma \geq 1$ and a continuous function $L_{0}:[0, \infty)^{2} \rightarrow[0, \infty)$ such that $|g(t, \xi, \eta)| \leq L_{0}(t, r)(1+\eta)^{\gamma}$, for all $t, \xi, \eta \geq 0$ with $\xi \leq r$. This, consequently, implies:

$$
|g(t, \xi, \eta)| \leq a+b \eta+\xi^{2} \eta \leq(a+b+\xi)(1+\eta)^{2} .
$$

3. There is a continuous function $\mu_{0}:[0, \infty)^{2} \rightarrow[0, \infty)$ so that $f(t, \xi, \eta)+g(t, \xi, \eta) \leq$ $\mu_{0}(t, r), \forall t, \xi, \eta \geq 0$ with $\xi \leq r$. This, consequently, implies:

$$
f(t, \xi, \eta)+g(t, \xi, \eta)=a-\xi \leq a .
$$

4. The solution $u_{1}(x, t)$ is still uniformly bounded as a function of $t$ in each bounded interval. To see this, one can refer to Lemma 2.2 in [54].

In fact, the aforementioned properties (1-4) can lead one to use Theorem 2, given in [55], and then to prove the next lemma.

Lemma 1. System (1) has a global continuous unique solution $\left(u_{1}, u_{2}\right)$, which is uniformly bounded in $\Omega \times[0, \infty)$, and $\exists M \in \mathbb{R}^{+}$such that:

$$
0 \leq u_{1}(x, t), u_{2}(x, t) \leq M, \quad \text { for all } x \in \Omega \text { and } t>0 .
$$

\section{Synchronization}

This section takes into consideration the drive-response formalism aiming to accomplish the synchronization of two coupled glycolysis systems. In this approach, we denote system (1) as the drive system and the other controlled system as the response system. Then, an appropriate controller is designed to force the errors of synchronization to converge to zero. The response system associated with system (1) can be given as follows:

$$
\left\{\begin{array}{cc}
\frac{\partial v_{1}}{\partial t}=d_{1} \Delta v_{1}+f\left(t, v_{1}, v_{2}\right)+U_{1}, & x \in \Omega, t>0 \\
\frac{\partial v_{2}}{\partial t}=d_{2} \Delta v_{2}+g\left(t, v_{1}, v_{2}\right)+U_{2}, & x \in \Omega, t>0 \\
\frac{\partial v_{1}}{\partial v}=\frac{\partial v_{2}}{\partial v}=0 & x \in \Omega, t>0
\end{array}\right.
$$


where $v_{i}=v_{i}(x, t),(i=1,2)$ are the states of system $(4)$ and $U=\left(U_{1}, U_{2}\right)$ are the target controls that need to be adjusted immediately.

As we have mentioned before, one of the key objectives of this work is to design an appropriate control $U$ for the purpose of forcing the error of synchronization $e(x, t)=$ $\left(e_{1}(x, t), e_{2}(x, t)\right)$ to converge to zero, in which this error can be defined via the differences between the states of system (1) and (4) as follows:

$$
\left(e_{1}, e_{2}\right)=\left(v_{1}-u_{1}, v_{2}-u_{2}\right) .
$$

In order to move forward to our next theoretical results, the definition below is stated for completeness.

Definition 1. The drive and response systems given, respectively, in (1) and (4) are considered to be globally synchronized if

$$
\lim _{t \rightarrow \infty}\|e(x, t)\|_{L^{2}}=0
$$

Lemma 2. There exists a positive constant $K$ such that

$$
\left|v_{2} v_{1}^{2}-u_{2} u_{1}^{2}\right| \leq K\left(\left|v_{1}-u_{1}\right|+\left|v_{2}-u_{2}\right|\right) .
$$

Proof. To begin with this proof, we first estimate the term $\left|v_{2} v_{1}^{2}-u_{2} u_{1}^{2}\right|$ as follows:

$$
\begin{aligned}
\left|v_{2} v_{1}^{2}-u_{2} u_{1}^{2}\right| & \leq\left|v_{2} v_{1}^{2}-u_{2} v_{1}^{2}\right|+\left|u_{2} v_{1}^{2}-u_{2} u_{1}^{2}\right| \\
& \leq\left|v_{1}^{2}\right|\left|v_{2}-u_{2}\right|+\left|u_{2}\right|\left|v_{1}-u_{1}\right|\left|v_{1}+u_{1}\right| \\
& \leq\left|v_{1}^{2}\right|\left|v_{2}-u_{2}\right|+\left|u_{2}\right|\left(\left|u_{1}\right|+\left|v_{1}\right|\right)\left|v_{1}-u_{1}\right| .
\end{aligned}
$$

Du to Lemma 1 , we observe that the states $u_{1}, u_{2}$, and $v_{1}$ are uniformly bounded. Therefore, there exist three positive constants $K_{1}, K_{2}$, and $K_{3}$ such that:

$$
\left|u_{1}\right| \leq K_{1},\left|u_{2}\right| \leq K_{2},\left|v_{1}\right| \leq K_{3} .
$$

Thus, we have

$$
\left|v_{2} v_{1}^{2}-u_{2} u_{1}^{2}\right| \leq K_{3}^{2}\left|v_{2}-u_{2}\right|+K_{2}\left(K_{1}+K_{3}\right)\left|v_{1}-u_{1}\right| .
$$

To finish the proof, one can choose a constant $K$ as follows:

$$
K=\max \left\{K_{3}^{2}, K_{2}\left(K_{1}+K_{3}\right)\right\},
$$

and hence the desired result will be held.

Theorem 1. The drive and response systems given, respectively, in (1) and (4) are globally synchronized according to the control law:

$$
\begin{aligned}
& U_{1}=(2 K+1) e_{1}-b e_{2}, \\
& U_{2}=(2 K+b) e_{2} .
\end{aligned}
$$

Proof. Using notation (5), we can obtain the following error system:

$$
\begin{cases}\frac{\partial e_{1}}{\partial t}=d_{1} \Delta e_{1}+b e_{2}-e_{1}+v_{1}^{2} v_{2}-u_{1}^{2} u_{2}+U_{1}, & \text { in } \Omega \times \mathbb{R}^{+}, \\ \frac{\partial e_{2}}{\partial t}=d_{2} \Delta e_{2}-b e_{2}-v_{1}^{2} v_{2}+u_{1}^{2} u_{2}+U_{2}, & \text { in } \Omega \times \mathbb{R}^{+} .\end{cases}
$$


Substituting the control law given in (6) and (7) into the above system yields:

$$
\begin{cases}\frac{\partial e_{1}}{\partial t}=d_{1} \Delta e_{1}-2 K e_{1}+v_{1}^{2} v_{2}-u_{1}^{2} u_{2}, & \text { in } \Omega \times \mathbb{R}^{+}, \\ \frac{\partial e_{2}}{\partial t}=d_{2} \Delta e_{2}-2 K e_{2}-v_{1}^{2} v_{2}+u_{1}^{2} u_{2}, & \text { in } \Omega \times \mathbb{R}^{+},\end{cases}
$$

which satisfies the zero Neumann boundary conditions. Now, we present our Lyapunov function as follows:

$$
V=\frac{1}{2} \int_{\Omega}\left(e_{1}^{2}+e_{2}^{2}\right) .
$$

This exactly implies:

$$
\frac{\partial V}{\partial t}=\int_{\Omega}\left(e_{1} \frac{\partial e_{1}}{\partial t}+e_{2} \frac{\partial e_{2}}{\partial t}\right)=\int_{\Omega}\left(d_{1} e_{1} \Delta e_{1}+d_{2} e_{2} \Delta e_{2}-2 K\left(e_{1}^{2}+e_{2}^{2}\right)+\left(v_{1}^{2} v_{2}-u_{1}^{2} u_{2}\right)\left(e_{1}-e_{2}\right) .\right.
$$

Consequently, using Green's identity leads us to obtain the following assertion:

$$
\begin{aligned}
\frac{\partial V}{\partial t} \leq & -\int_{\Omega} d_{1}\left|\nabla e_{1}\right|^{2} d x+\int_{\partial \Omega} d_{1} e_{1} \frac{\partial e_{1}}{\partial \eta} d \sigma-\int_{\Omega} d_{2}\left|\nabla e_{2}\right|^{2} d x \\
& +\int_{\partial \Omega} d_{2} e_{2} \frac{\partial e_{2}}{\partial \eta} d \sigma-2 K \int_{\Omega}\left(e_{1}^{2}+e_{2}^{2}\right) d x+\int_{\Omega}\left|v_{1}^{2} v_{2}-u_{1}^{2} u_{2}\right|\left|e_{1}-e_{2}\right| d x .
\end{aligned}
$$

With the help of Lemma 2, together with the Neumann boundary conditions, the term $\frac{\partial V}{\partial t}$ will be turned to be in the following estimation:

$$
\begin{aligned}
\frac{\partial V}{\partial t} & \leq-\int_{\Omega} d_{1}\left|\nabla e_{1}\right|^{2} d x-\int_{\Omega} d_{2}\left|\nabla e_{2}\right|^{2} d x-2 K \int_{\Omega}\left(e_{1}^{2}+e_{2}^{2}\right) d x \\
& =K\left|e_{1}+e_{2}\right|\left|e_{1}-e_{2}\right| \\
& \left.\leq-\int_{\Omega}\left[d_{1}\left|\nabla e_{1}\right|^{2}+d_{2}\left|\nabla e_{2}\right|^{2}\right)\right]-2 K \int_{\Omega}\left(\left|e_{1}\right|^{2}+\left|e_{2}\right|^{2}\right) d x+K \int_{\Omega}\left(\left|e_{1}\right|+\left|e_{2}\right|\right)^{2} d x \\
& \left.=-\int_{\Omega}\left[d_{1}\left|\nabla e_{1}\right|^{2}+d_{2}\left|\nabla e_{2}\right|^{2}\right)\right]-K \int_{\Omega}\left(\left|e_{1}\right|-\left|e_{2}\right|\right)^{2} d x
\end{aligned}
$$

That is;

$$
\frac{\partial V}{\partial t}<0
$$

From the perspective of Lyapunov's stability theory, which asserts the global asymptotic stability of the trivial solution to the error system (9), the drive system (1) and the response system (4) are globally synchronized, which completes the proof.

\section{Numerical Simulations}

In this section, we demonstrate some computational examples in one- and twodimensional space to exemplify the practicability of the synchronization scheme proposed in this work. These simulations are carried out using some prepared codes in MATLAB based on the finite difference method (FDM), see [56,57] for a full overview of this scheme and how it could be implemented in synchronization problems. First of all, let us take $x \in \Omega=[0,10]$ with a step size equal to $0.2, t \in[0,100]$ with a step size equal to $4,\left(d_{1}, d_{2}, a, b\right)=(0.01,1,3.5,0.25)$ and the initial conditions associated with the drive system (1) as follows:

$$
\left(u_{1}(x, 0), u_{2}(x, 0)\right)=(3.5+0.1 \sin (x), 0.28+0.1 \sin (x)),
$$


and the initial conditions associated with the response system (4) as follows:

$$
\left(v_{1}(x, 0), v_{2}(x, 0)\right)=(1+0.5 \sin (0.2 x), 0.6+0.5 \sin (0.2 x)) .
$$

The spatiotemporal solutions of system (1) and system (4) with homogeneous Neumann boundary conditions are depicted in Figures 1 and 2, whereas Figures 3 and 4 show the pattern formation associated with the two systems (1) and (4), respectively. In accordance with Theorem 1 , if we choose $K=\frac{1}{5}$, then the two controllers $U_{1}$ and $U_{2}$ will be designed as follows:

$$
\begin{aligned}
& U_{1}=\frac{5}{7}\left(v_{1}-u_{1}\right)-b\left(v_{2}-u_{2}\right), \\
& U_{2}=\frac{5 b+2}{5}\left(v_{2}-u_{2}\right),
\end{aligned}
$$

and then system (1) and system (4) will be globally synchronized. To illustrate this numerically, the spatiotemporal solutions of the error synchronization system (5) are provided in Figures 5 and 6 in one- and two-dimensional space. Indeed, this evolution clearly indicates that the errors converge to 0 as $t \rightarrow+\infty$.
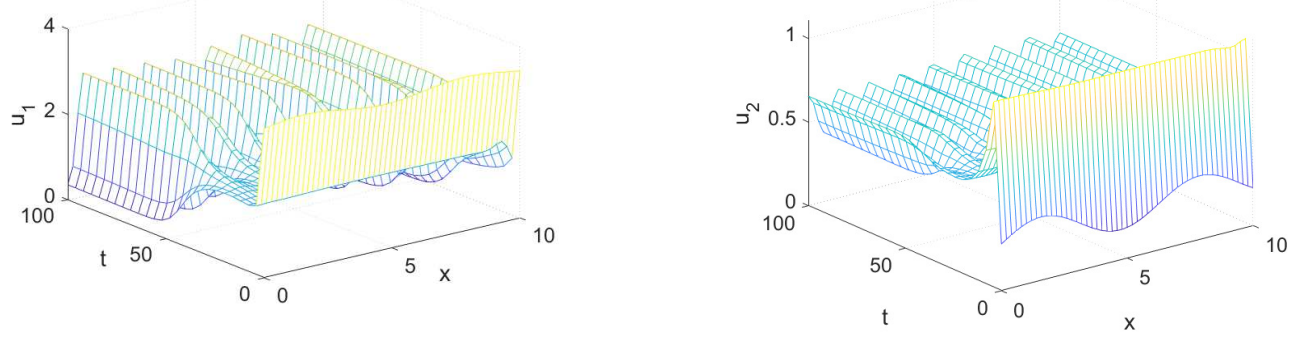

Figure 1. Dynamic behavior of the drive system (1) with $d_{1}=0.01, d_{2}=1, a=3.5$, and $b=0.25$ in accordance with the initial conditions given in (10).
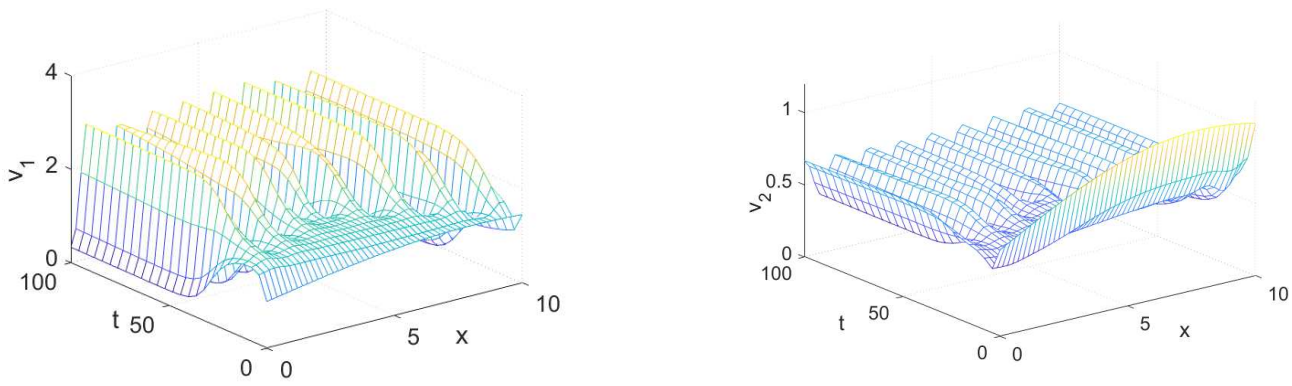

Figure 2. Dynamic behavior of the response system (4) with $d_{1}=0.01, d_{2}=1, a=3.5$, and $b=0.25$ in accordance with the initial conditions given in (11). 

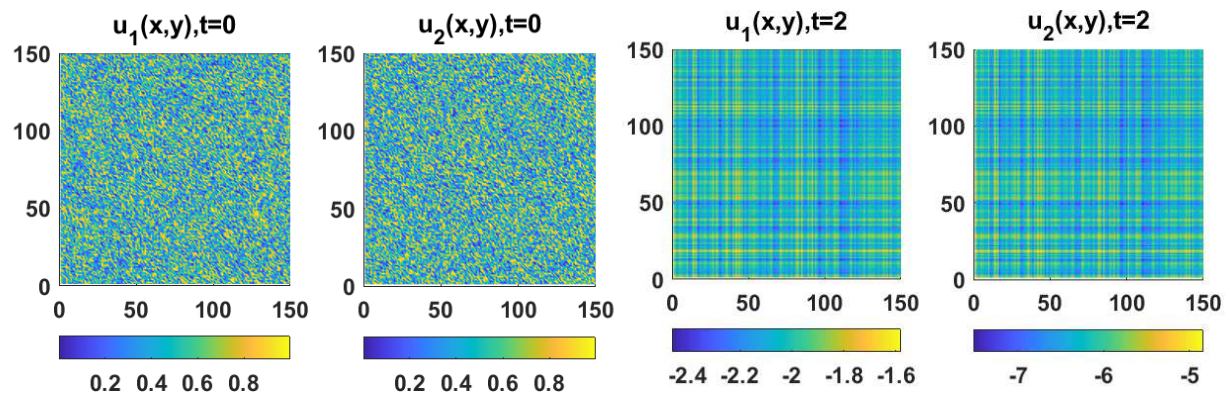

(a) $t=0$

(b) $t=1$
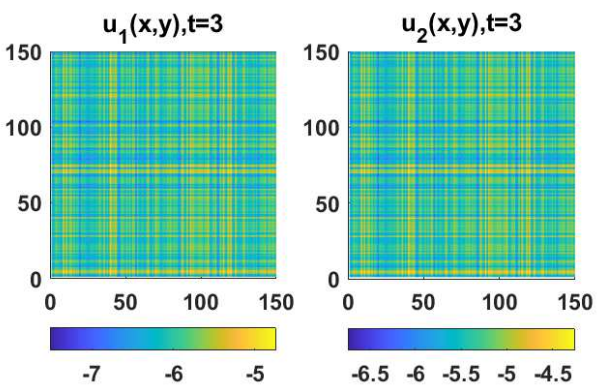

(c) $t=3$

Figure 3. The solution of the drive system (1) in $2 D$ space at (a) $t=0,(\mathbf{b}) t=1$, and (c) $t=3$.

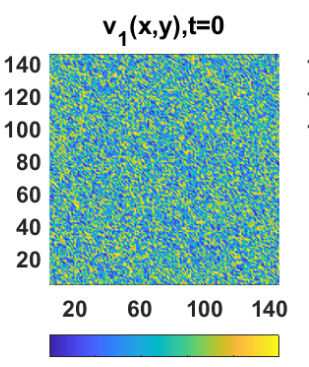

$\begin{array}{lllll}0.2 & 0.4 & 0.6 & 0.8\end{array}$

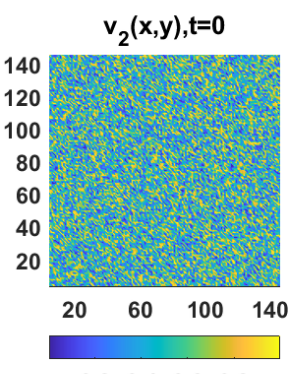

$\begin{array}{llll}0.2 & 0.4 & 0.6 & 0.8\end{array}$

(a) $t=0$
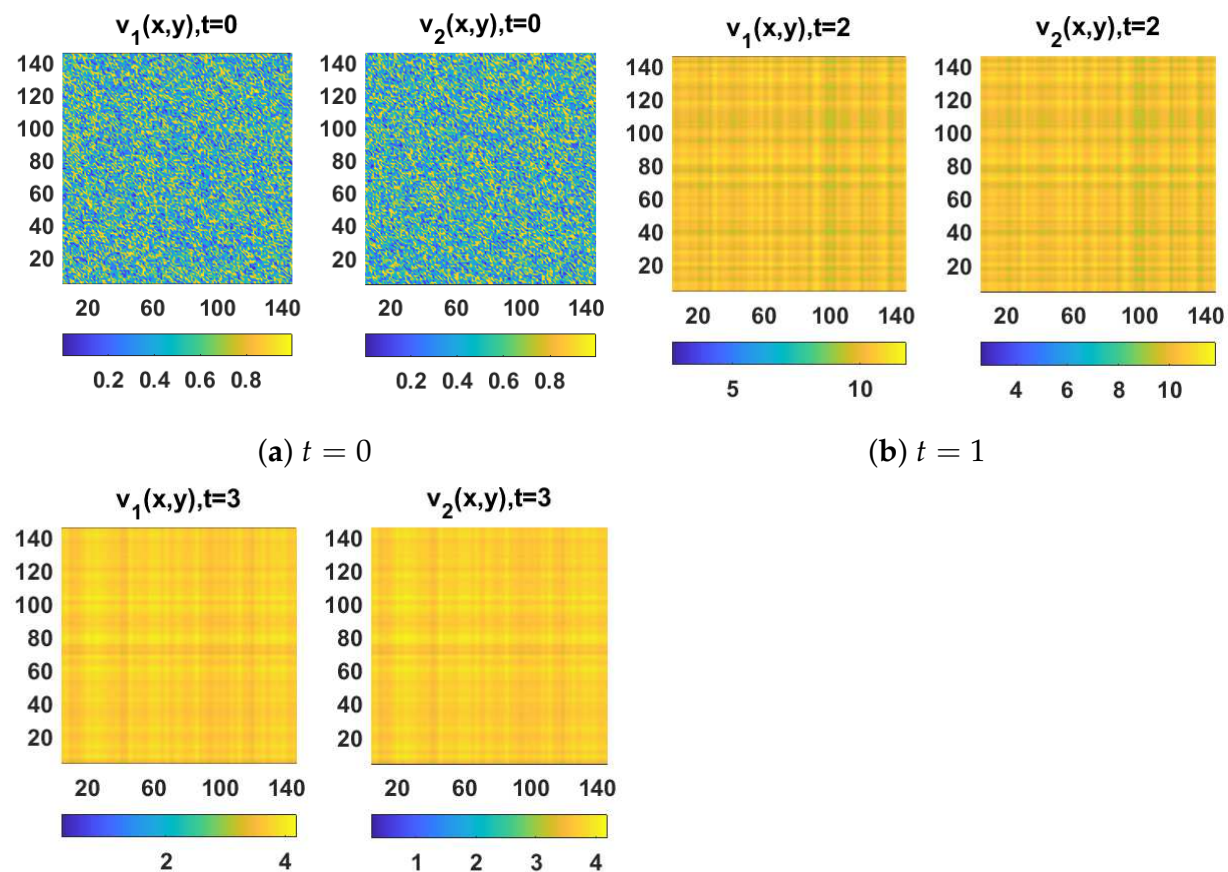

(b) $t=1$

(c) $t=3$

Figure 4. The solution of the response system (4) in $2 D$ space at (a) $t=0,(\mathbf{b}) t=1$, and (c) $t=3$. 

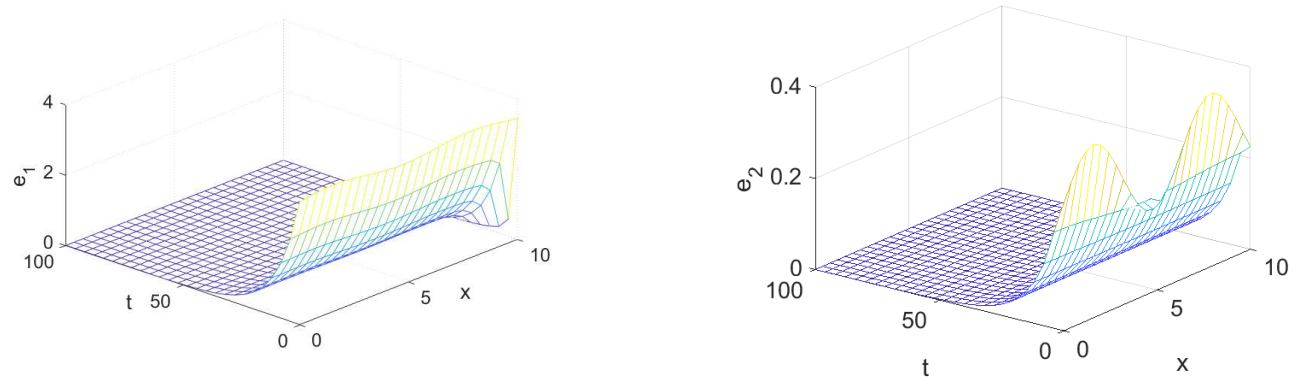

Figure 5. Dynamic behavior of the solutions of the spatiotemporal synchronization error system (5) with $d_{1}=0.01, d_{2}=1$, and $K=0.2$.
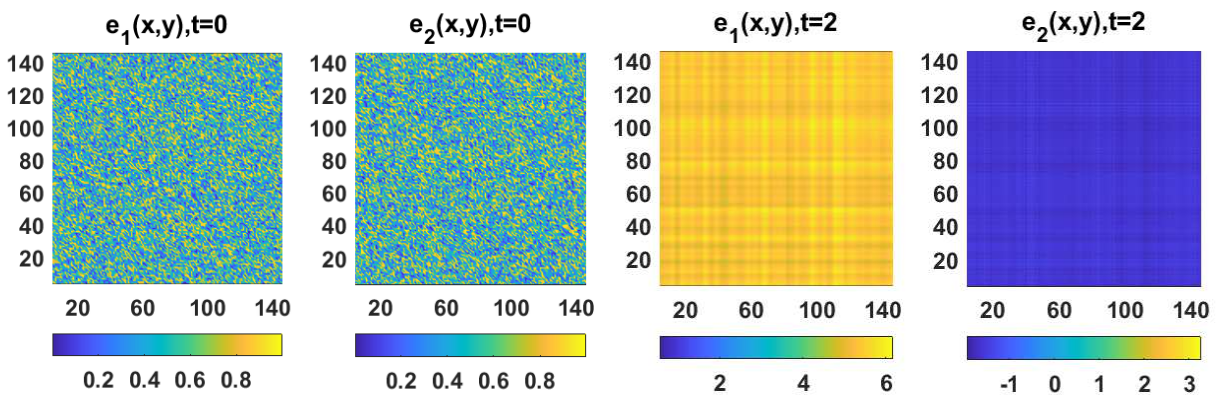

(a) $t=0$

(b) $t=1$
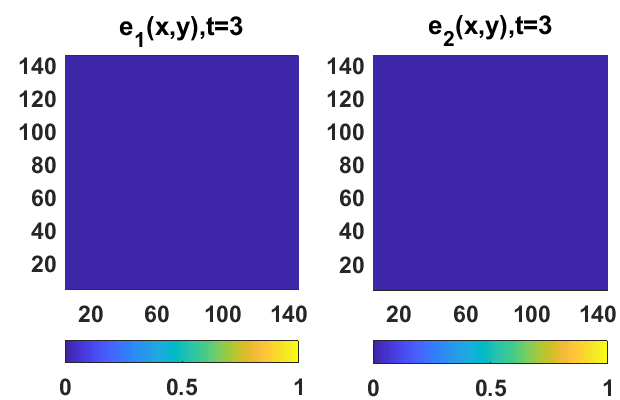

(c) $t=3$

Figure 6. The solution of the spatiotemporal synchronization error system (5) in $2 D$-space at (a) $t=0$, (b) $t=1$, and (c) $t=3$.

\section{Conclusions}

For many years, many researchers have focused on the study of the synchronization of systems of ordinary differential equations and uni-dimensional maps. In the present work, we have developed an innovative approach to analyze the control synchronization of the nonlinear glycolysis spatiotemporal system. We first established the uniform boundedness of the solution, which was subsequently used in the implementation of the proposed control law. Then, we proved our findings rigorously using the Lyapunov direct method. Several numerical simulations have been illustrated to provide evidence of the efficacy and the performance of the established control approaches. In this regard, the simulation results have confirmed that the proposed control scheme is efficient for the purpose of synchronization. As a future research plan, we can focus on the use of optimal control techniques for the stabilization and synchronization of chaotic dynamical attractors employed in several applications, such as secure communications, applications for encryption, data sovereignty control, and many others.

Author Contributions: Conceptualization, A.O., I.M.B., S.B., J.L., H.J., A.A.A. and A.H.A.; methodology, A.O., I.M.B., S.B., J.L., H.J., A.A.A. and A.H.A.; software, A.O., I.M.B., S.B., J.L., H.J., A.A.A. and A.H.A.; validation, A.O., I.M.B., S.B., J.L., H.J., A.A.A. and A.H.A.; formal analysis, A.O., I.M.B., 
S.B., J.L., H.J., A.A.A. and A.H.A.; investigation, A.O., I.M.B., S.B., J.L., H.J., A.A.A. and A.H.A.; resources, A.O., I.M.B., S.B., J.L., H.J., A.A.A. and A.H.A.; data curation, A.O., I.M.B., S.B., J.L., H.J., A.A.A. and A.H.A.; writing-original draft preparation, A.O., I.M.B., S.B., J.L., H.J., A.A.A. and A.H.A.; writing-review and editing, A.O., I.M.B., S.B., J.L., H.J., A.A.A. and A.H.A.; supervision, A.O., I.M.B., S.B., J.L., H.J., A.A.A. and A.H.A. All authors have read and agreed to the published version of the manuscript.

Funding: This research was supported by the Taif University Researchers Supporting Project number (TURSP-2020/349), Taif University, Taif, Saudi Arabia.

Institutional Review Board Statement: Not applicable.

Informed Consent Statement: Not applicable.

Conflicts of Interest: The authors declare no conflict of interest.

\section{References}

1. Eroglu, D.; Lamb, J.S.W.; Pereira, T. Synchronisation of chaos and its applications. Contemp. Phys. 2017, 58, 207-243. [CrossRef]

2. Srivastava, M.; Ansari, S.P.; Agrawal, S.K.; Das, S.; Leung, A.Y.T. Anti-synchronization between identical and non-identical fractional-order chaotic systems using active control method. Nonlinear Dyn. 2014, 76, 905-914 [CrossRef]

3. Odibat, Z.M.; Corson, N.; Aziz-Alaoui, M.A.; Bertelle, C. Synchronization of chaotic fractional-order systems via linear control. Int. J. Bifurc. Chaos 2010, 20, 81-97. [CrossRef]

4. Chen, X.R.; Liu, C.X. Chaos synchronization of fractional order unified chaotic system via nonlinear control. Int. J. Mod. Phys. B 2011, 25, 407-415. [CrossRef]

5. Agrawal, S.K.; Das, S. A modified adaptive control method for synchronization of some fractional chaotic systems with unknown parameters. Nonlinear Dyn. 2013, 73, 907-919. [CrossRef]

6. Odibat, Z.M. Adaptive feedback control and synchronization of non-identical chaotic fractional order systems. Nonlinear Dyn. 2010, 60, 479-487. [CrossRef]

7. Jahanshahi, H. Smooth control of HIV / AIDS infection using a robust adaptive scheme with decoupled sliding mode supervision. Eur. Phys. J. Spec. Top. 2018, 227, 707-718. [CrossRef]

8. Jahanshahi, H.; Rajagopal, K.; Akgul, A.; Sari, N.N.; Namazi, H.; Jafari, S. Complete analysis and engineering applications of a megastable nonlinear oscillator. Int. J. Non-Linear Mech. 2018, 107, 126-136. [CrossRef]

9. Jahanshahi, H.; Shahriari-Kahkeshi, M.; Alcaraz, R.; Wang, X.; Singh, V.P.; Pham, V.-T. Entropy analysis and neural network-based adaptive control of a non-equilibrium four-dimensional chaotic system with hidden attractors. Entropy 2019, 21, 156. [CrossRef]

10. Jahanshahi, H.; Yousefpour, A.; Munoz-Pacheco, J.M.; Moroz, I.; Wei, Z.; Castillo, O. A new multi-stable fractional-order fourdimensional system with self-excited and hidden chaotic attractors: Dynamic analysis and adaptive synchronization using a novel fuzzy adaptive sliding mode control method. Appl. Soft Comput. 2020, 87, 105943. [CrossRef]

11. Jahanshahi, H.; Yousefpour, A.; Munoz-Pacheco, J.M.; Kacar, S.; Pham, V.-T.; Alsaadi, F.E. A new fractional-order hyperchaotic memristor oscillator: Dynamic analysis, robust adaptive synchronization, and its application to voice encryption. Appl. Math. Comput. 2020, 383, 125310. [CrossRef]

12. Wang, B.; Jahanshahi, H.; Bekiros, S.; Chu, Y.-M.; Gomez-Aguilar, J.F.; Alsaadi, F.E. Tracking control and stabilization of a fractional financial risk system using novel active finite-time fault-tolerant controls. Fractals 2021, 29, 2150155-77. [CrossRef]

13. Wang, B.; Jahanshahi, H.; Volos, C.; Bekiros, S.; Khan, M.A.; Agarwal, P. A New RBF Neural Network-Based Fault-Tolerant Active Control for Fractional Time-Delayed Systems. Electronics 2021, 10, 1501. [CrossRef]

14. Xiong, P.-Y.; Jahanshahi, H.; Alcaraz, R.; Chu, Y.-M.; Gómez-Aguilar, J.F.; Alsaadi, F.E. Spectral entropy analysis and synchronization of a multi-stable fractional-order chaotic system using a novel neural network-based chattering-free sliding mode technique. Chaos Solitons Fractals 2021, 144, 110576. [CrossRef]

15. Jahanshahi, H.; Sajjadi, S.S.; Bekiros, S.; Aly, A.A. On the development of variable-order fractional hyperchaotic economic system with a nonlinear model predictive controller. Chaos Solitons Fractals 2021, 144, 110698. [CrossRef]

16. Razminia, A.; Baleanu, D. Complete synchronization of commensurate fractional order chaotic systems using sliding mode control. Mechatronics 2013, 23, 873-879. [CrossRef]

17. Al-sawalha, M.M.; Alomari, A.K.; Goh, S.M.; Nooran, M.S.M. Active antisynchronization of two identical and different fractionalorder chaotic systems. Int. J. Nonlinear Sci. 2011, 11, 267-274.

18. Si, G.; Sun, Z.; Zhang, Y.; Chen, W. Projective synchronization of different fractional-order chaotic systems with non-identical orders. Nonlinear Anal. Real World Appl. 2012, 13, 1761-1771. [CrossRef]

19. Yi, C.; Liping, C.; Ranchao, W.; Juan, D. Q-S synchronization of the fractionalorder unified system. Pramana 2013, 80, 449-461.

20. Feng, H.; Yang, Y.; Yang, S.P. A new method for full state hybrid projective synchronization of different fractional order chaotic systems. Appl. Mech. Mater. 2013, 385, 919-922. [CrossRef]

21. Zhang, X.D.; Zhao, P.D.; Li, A.H. Construction of a new fractional chaotic system and generalized synchronization. Commun. Theor. Phys. 2010, 53, 1105-1110. 
22. Ouannas, A.; Al-sawalha, M.M. On $\Lambda-\varphi$ generalized synchronization of chaotic dynamical systems in continuous-time. Eur. Phys. J. Spec. Top. 2016, 225, 187-196. [CrossRef]

23. Ouannas, A.; Al-sawalha, M.M.; Ziar, T. Fractional chaos synchronization schemes for different dimensional systems with non-identical fractional-orders via two scaling matrices. Optik 2016, 127, 8410-8418. [CrossRef]

24. Jahanshahi, H.; Chen, D.; Chu, Y.-M.; Gómez-Aguilar, J.F.; Aly, A.A. Enhancement of the performance of nonlinear vibration energy harvesters by exploiting secondary resonances in multi-frequency excitations. Eur. Phys. J. Plus. 2021, 136, 1-22. [CrossRef]

25. Li, J.-F.; Jahanshahi, H.; Kacar, S.; Chu, Y.-M.; Gómez-Aguilar, J.F.; Alotaibi, N.D. On the variable-order fractional memristor oscillator: Data security applications and synchronization using a type-2 fuzzy disturbance observer-based robust control. Chaos Solitons Fractals 2021, 145, 110681. [CrossRef]

26. Wang, Y.-L.; Jahanshahi, H.; Bekiros, S.; Bezzina, F.; Chu, Y.-M.; Aly, A.A. Deep recurrent neural networks with finite-time terminal sliding mode control for a chaotic fractional-order financial system with market confidence. Chaos Solitons Fractals 2021, 146, 110881. [CrossRef]

27. Bekiros, S.; Jahanshahi, H.; Bezzina, F.; Aly, A.A. A novel fuzzy mixed H2/H optimal controller for hyperchaotic financial systems. Chaos Solitons Fractals 2021, 146, 110878. [CrossRef]

28. Wang, H.; Jahanshahi, H.; Wang, M.-K.; Bekiros, S.; Liu, J.; Aly, A.A. A Caputo-Fabrizio Fractional-Order Model of HIV/AIDS with a Treatment Compartment: Sensitivity Analysis and Optimal Control Strategies. Entropy 2021, 23, 610. [CrossRef]

29. Wang, B.; Jahanshahi, H.; Volos, C.; Bekiros, S.; Yusuf, A.; Agarwal, P. Control of a symmetric chaotic supply chain system using a new fixed-time super-twisting sliding mode technique subject to control input limitations. Symmetry 2021, 13, 1257. [CrossRef]

30. Liu, Z.; Jahanshahi, H.; Gómez-Aguilar, J.F.; Fernandez-Anaya, G.; Torres-Jiménez, J.; Aly, A.A.; Aljuaid, A.M. Fuzzy adaptive control technique for a new fractional-order supply chain system. Phys. Scripta. 2021, 96, 124017. [CrossRef]

31. Wang, B.; Jahanshahi, H.; Dutta, H.; Zambrano-Serrano, E.; Grebenyuk, V.; Bekiros, S. Incorporating fast and intelligent control technique into ecology: A Chebyshev neural network-based terminal sliding mode approach for fractional chaotic ecological systems. Ecol. Complex. 2021, 47, 100943. [CrossRef]

32. Ahmed, N.; Tahira, S.S.; Imran, M.; Rafiq, M.; Rehman, M.A.; Younis, M. Numerical analysis of auto-catalytic glycolysis model. Aip Adv. 2019, 9, 085213. [CrossRef]

33. Baleanua, D.; Inc, M.; Yusuf, A.; Aliyu, A.I. Lie symmetry analysis, exact solutions and conservation laws for the time fractional modified Zakharov-Kuznetsov equation. Nonlinear Anal. Model. Control 2017, 22, 861-876. [CrossRef]

34. Younis, M.; Rizvi, S.T.R. Optical soliton like-pulses in ring-cavity fiber lasers of carbon nanotubes. Nanoelectron. Optoelectron. 2016, 11, 276-279. [CrossRef]

35. Zhou, J.; Shi, J. Pattern formation in a general glycolysis reaction-diffusion system. J. Appl. Math. 2015, 80, 1703-1738. [CrossRef]

36. Romano, A.H.; Conway, T. Evolution of carbohydrate metabolic pathways. Res. Microbiol. 1996, 147, 448-455. [CrossRef]

37. Lane, A.N.; Fan, T.W.M.; Higashi, R.M. Metabolic acidosis and the importance of balanced equation. Metabolomics 2009, 5, 163-165. [CrossRef]

38. SelKov, E.E. Self-oscillation in glycolysis 1. A simple model. Eur. J. Biochem. 1968, 4, 79-86. [CrossRef] [PubMed]

39. Strogatz, S.H. Nonlinear Dynamics and Chaos with Applications to Physics, Biology, Chemistry, and Engineering; Adisson-Wesley: New York, NY, USA, 1994.

40. Mesdoui, F.; Ouannas, A.; Shawagfeh, N.; Grassi, G.; Pham, V.-T. Synchronization Methods for the Degn-Harrison ReactionDiffusion Systems. IEEE Access 2020, 8, 91829-91836. [CrossRef]

41. Wu, F.; Wang, Y.; Ma, J.; Jin, W.; Hobiny, A. Multi-channels coupling-induced pattern transition in a tri-layer neuronal network. Phys. Stat. Mech. Its Appl. 2018, 493, 54-68. [CrossRef]

42. Ambrosio, B.; Aziz-Alaoui, M.A. Synchronization and control of coupled reaction-diffusion systems of the FitzHugh-Nagumo type. Comput. Math. Appl. 2012, 64, 934-943. [CrossRef]

43. Mansouri, D.; Bendoukha, S.; Abdelmalek, S.; Youkana, A. On the complete synchronization of a time-fractional reaction-diffusion system with the Newton-Leipnik nonlinearity. Appl. Anal. 2019, 100, 675-694. [CrossRef]

44. Parekh, N.; Kumar, V.R.; Kulkarni, B.D. Control of spatiotemporal chaos: A study with an autocatalytic reaction-diffusion system. Pramana J. Phys. 1997, 48, 303-323. [CrossRef]

45. García, P.; Acosta, A.; Leiva, H. Synchronization conditions for master-slave reaction diffusion systems. EPL 2009, 88, 60006. [CrossRef]

46. Wu, K.-N.; Tian, T.; Wang, L. Synchronization for a class of coupled linear partial differential systems via boundary control. J. Frankl. Inst. 2016, 353, 4062-4073. [CrossRef]

47. Wang, L.; Zhao, H. Synchronized stability in a reaction-diffusion neural network model. Phys. Lett. A 2014, 378, 3586-3599. [CrossRef]

48. Ouannas, A.; Abdelli, M.; Odibat, Z. Synchronization Control in Reaction-Diffusion Systems: Application to Lengyel-Epstein System. Complexity 2019, 2019, 8. [CrossRef]

49. Mesdoui, F.; Shawagfeh, N.; Ouannas, A. Global synchronization of fractional-order and integer-order N component reaction diffusion systems: Application to biochemical models. Math. Meth. Appl. Sci. 2020, 44, 1003-1012. [CrossRef]

50. Westermark, P.O.; Lansner, A. A Model of Phosphofructokinase and Glycolytic Oscillations in the Pancreatic $\beta$-cell. Biophys. J. 2003, 85, 126-139. [CrossRef] 
51. Bhargava, S.C. On the higgins model of glycolysis. Bull. Math. Biol. 1980, 42, 829-836. [CrossRef]

52. Peng, R. Qualitative analysis of steady states to the Sel'kov model. J. Differ. Equ. 2007, 241, 386-398. [CrossRef]

53. Lee, K.J.; Swinney, H.L. Replicating Spots in Reaction-Diffusion Systems. Int. J. Bifurc. Chaos 1997, 07, 1149-1158. [CrossRef]

54. You, Y. Asymptotical dynamics of Selkov equations. Discret. Contin. Dyn. Syst. 2009, 2, 193. [CrossRef]

55. Hollis, S.L.; Martin, R.H., Jr.; Pierre, M. Global Existence and Boundedness in Reaction-Diffusion Systems. SIAM J. Math. Anal. 1987, 18, 744-761. [CrossRef]

56. Baleanu, D.; Zibaei, S.; Namjoo, M.; Jajarmi, A. A nonstandard finite difference scheme for the modeling and nonidentical synchronization of a novel fractional chaotic system. Adv. Differ. Equ. 2021, 2021, 308. [CrossRef]

57. Han, Y.; Zhao, J. Accurate substrate analysis based on a novel finite difference method via synchronization method on layered and adaptive meshing. IEEE Trans. Comput. Aided Des. Integr. Circuits Syst. 2013, 32, 1520-1532. [CrossRef] 